\title{
L'étranger e a transposição midiática Killing an Arab
}

L'étranger and the mediatic transposition Killing an Arab

\section{Victória Elizabeth dos Santos \\ Ana Luiza Ramazzina Ghirardi}

Universidade Federal de São Paulo - UNIFESP - São Paulo - Brasil

\begin{abstract}
Resumo: O presente artigo tem como objetivo analisar como ocorre a transposição midiática do romance L'étranger (1942) de Albert Camus para a música Killing an Arab (1978) da banda inglesa The Cure. A partir de trechos selecionados do romance e da letra da música, foi possível fazer diferenciações pelo contexto histórico de produção das duas obras, analisá-las segundo conceitos de intertextualidade de Koch (2012) e Marcuschi (2008). Para definições de transmodalização e intermidialidade foram utilizados Gaudreault (2008), Clüver (2007), Rajewski (2012) e Genette (2006). Foi feita também uma análise direta dos trechos das obras, estabelecendo suas semelhanças e diferenças a partir da leitura dos conceitos estudados por Silva (2013).
\end{abstract}

Palavras-chave: Intermidialidade. Transmodalização. Intertextualidade. Albert Camus. The Cure.

Abstract: The article aims at analyzing mediact transposition of Albert Camus' novel L'étranger (1942) into the song Killing an Arab (1978) by the British band The Cure. Excerpts from the song and the novel were discussed having as historical background the context for the production of both works and as theoretical framework the studies on intertextuality by Koch (2012) and Marcuschi (2008). Gaudreault (2008), Clüver (2007), Rajewski (2012) and Genette (2006) were the basis for the discussions on transmodalization and intermediality. Silva (2013) was the reference for the direct analysis and contrast of the excerpts..

Keywords: Intermediality. Transmodalization. Intertextuality. Albert Camus. The Cure. 


\section{Introdução}

O presente artigo apresenta o cotejo de dois gêneros distintos: o fragmento de um romance francês e a letra de uma música britânica. Ambos são considerados tipos relativamente estáveis de enunciados, pois se encontram em esferas da língua que Ihes são adequadas. Segundo Bakhtin (1997, p. 1), "Qualquer enunciado considerado isoladamente é, claro, individual, mas cada esfera de utilização da língua elabora seus tipos relativamente estáveis de enunciados, sendo isso que denominamos gêneros do discurso". Considerados isoladamente, ambos os textos podem ser ditos individuais, únicos. Contudo, quando se postula a existência de uma relação entre duas produções textuais, mesmo que pertençam a diferentes gêneros, é possível realizar um trabalho de categorização, o que permite estabelecer semelhanças e diferenças entre ambas.

Os dois trabalhos artísticos estudados, L'étranger (1942), de Albert Camus e Killing an Arab (1978), de Robert Smith apresentam dinâmicas diferentes de recepção e funcionamento; as diferenças que apresentam podem ser classificadas em categorias variadas, que serão analisadas ao longo desse artigo.

\section{Variações estruturais sobre o mesmo tema}

L'étranger é um romance, escrito por Albert Camus e publicado na França em 1942; já Killing an Arab é uma canção, escrita por Robert Smith e lançada na Inglaterra em 1978. A segunda obra estabelece, entretanto, um diálogo com a primeira ainda que 36 anos separem os momentos de produção de um trabalho e de outro, e que os gêneros respectivos sejam diversos.

Considerando que a obra de Camus é um romance, pode-se dizer a respeito da estrutura desse gênero:

É característica do romance contemporâneo a assimilação à sua própria estrutura da relatividade da perspectiva, da consciência, do espaço e do tempo. Tais questionamentos, tão frequentes na atualidade, são levantados nessas narrativas, não somente através do seu conteúdo, mas também da sua forma. À ordem lógica da oração e à coerência estrutural e cronológica dos textos clássicos, correspondem uma sintaxe e uma estética textuais mais livres, empenhadas na valorização da subjetividade do narrador e de seus personagens, empenhadas em "reproduzir com a máxima fidelidade a experiência psíquica” (ROSENFELD, 1976, p. 84).

A observação de Rosenfeld (1976), pode ser ilustrada pela passagem de L'étranger, em que o protagonista do romance descreve suas atividades diárias:

J'ai pris l'autobus à 2 heures. II faisait très chaud. J'ai mangé au restaurant, chez Céleste, comme d'habitude. Ils avaient tous beaucoup de peine pour moi et Céleste m'a dit «On n'a qu'une mère. » Quand je suis parti, ils m'ont accompagné à la porte. J'étais un peu étourdi parce qu'il a fallu que je monte chez Emmanuel pour lui emprunter une cravate noire et un brassard. II a perdu son oncle, il y a quelques mois (CAMUS, 2015, p. 10) ${ }^{1}$.

No trecho acima, o ponto de vista priorizado é o do próprio narrador, Meursault, personagem principal de sua história; é possível acompanhar suas atividades diárias através de suas próprias palavras e experiências, o que caracteriza o romance como estruturado a partir de uma perspectiva subjetiva. Não apenas Meursault, como também outras personagens que aparecem no trecho, expressam sentimentos relacionados ao luto, uma vez que a mãe do protagonista havia morrido, segundo a cronologia narrativa, somente algumas horas antes, o que resulta em compadecimento dessas personagens com o narrador. Para concluir o trecho, insere-se uma ideia cultural a respeito dos ritos funerários. Ao sair do restaurante de Céleste para ir até a casa de Emmanuel em busca de roupas específicas, admitese que há um protocolo a ser seguido em relação às vestimentas a serem utilizadas em velórios e enterros; mesmo que isso seja evidenciado de forma sutil, fica evidente que, à época da narrativa, homens

\footnotetext{
1 "Peguei o ônibus às duas horas. Fazia muito calor. Como de costume, almocei no restaurante do Céleste. Estavam todos com muita pena de mim e Céleste disse-me: 'Mãe, só tem uma.' Quando saí, acompanharam-me até a porta. Estava um pouco atordoado porque foi preciso ir à casa de Emmanuel para the pedir emprestadas uma braçadeira e uma gravata preta. Ele perdeu o tio há alguns meses". (CAMUS, 2013, p. 13)
} 
em geral usam braçadeira e gravata preta nessas situações.

Feitas essas considerações, pode-se afirmar que o narrador constrói suas ações a partir do seu próprio ponto de vista, característica apontada por Rosenfeld como sendo particular dos romances contemporâneos.

Killing an Arab apresenta uma estrutura, em versos, típica do gênero canção e propõe, também, uma visada subjetiva.

No que diz respeito ao narrador, é possível identificar uma marca de pessoalidade em ambas as obras, próprias de textos caracterizados pela presença de um narrador homodiegético ${ }^{2}$. Contudo, ao recorrer a Genette (1972), é possível propor também a existência de um outro tipo de narrador, que define melhor 0 personagem Meursault, o autodiegético, aquele que não somente participa da história contada, como também é seu personagem principal.

Como dito acima, a narração de L'étranger é realizada por Meursault, personagem principal da história. O excerto a seguir se refere a uma das situações iniciais do romance em que o personagem vai ao asilo em que ocorrerá o velório de sua mãe. $\mathrm{Na}$ passagem, fica evidente mais uma vez a pessoalidade a partir da qual a narrativa é construída, com o uso abundante de pronomes na primeira pessoa, além da sequenciação de acontecimentos voltados para a vida do próprio narrador:

"L'asile de vieillards est à Marengo, à quatrevingts kilomètres d'Alger. Je prendrai l'autobus à 2 heures et j'arriverai dans l'après-midi. Ainsi, je pourrai veiller et je rentrerai demain soir. J'ai demandé deux jours de congé à mon patron et il ne pouvait pas me les refuser avec une excuse pareille". (CAMUS, 2015, p. 9) ${ }^{3}$

\footnotetext{
2 De acordo com o modelo proposto por Genette, Stam/Burgoyne/Flitterman-Lewis distinguem dois tipos de narrador. Por um lado, encontramos o Narrador intradiegético. Trata-se de um narrador que é simultaneamente personagem, no mundo ficcional. Se é personagem e narrador da sua própria história, é um narrador homodiegético, como acontece com os narradores em Citizen Kane. Se a personagem-narrador não pertence à história que está a narrar, será um narrador heterodiegético. Por outro lado, existe o Narrador extradiegético. Será o narrador externo, que regula registros visuais e sonoros e se manifesta através de códigos cinematográficos e distintos canais de expressão e não através de um discurso verbal (CARDOSO, 2003, p. 58. Grifos do autor).

3 "O asilo dos velhos fica em Marengo, a oitenta quilômetros de Argel. Vou tomar o ônibus às duas horas e chego ainda à tarde.
}

Em Killing an Arab, não se pode afirmar nem o nome do personagem narrador nem mesmo sua identidade. Contudo, é possível notar a presença de um narrador incluso na própria história atuando como seu principal agente:

I'm standing on a beach

With a gun in my hand

Staring at the sky

Staring at the sand (The Cure -Killing an Arab) ${ }^{4}$.

Também se faz relevante indicar que uma das principais mudanças estruturais entre as duas produções se refere à língua em que foram escritas. Camus, escritor argelino de nascimento, tinha como um de seus idiomas o francês. Sobre a formação de Camus, pode-se observar que o autor:

Era pied-noir, pé preto, argelino. Conviveu com o colonialismo francês e cresceu em um país castigado pelo subdesenvolvimento. Formou-se em filosofia na Universidade de Argel. Conseguiu penetrar no círculo de intelectuais franceses nas décadas de 1940 e 50.

Já Robert Smith, compositor de Killing an Arab, membro da banda The Cure, nasceu em Blackpool, cidade da Inglaterra, cuja língua oficial é o inglês. Fica portanto evidente que há uma diferença significativa no código linguístico-cultural de suas produções que leva cada autor a decisões diferentes em suas criações a partir da materialidade de cada idioma.

\section{Duas mídias, dois contextos históricos}

Trinta e seis anos separam a publicação do romance de Camus e a música de The Cure. Três décadas de intervalo remetem o olhar para mudanças significativas no contexto histórico que permeava as produções culturais e artísticas das respectivas épocas.

No caso de L'étranger, por exemplo, o mundo, e em especial a Europa, se via marcado pela

Assim posso velar o corpo e estar de volta amanhã à noite. Pedi dois dias de licença a meu patrão e, com uma desculpa destas, ele não podia recusar." (CAMUS, 2013, p. 13) Fonte: $O$ Estrangeiro de Albert Camus: Filosofia e Linguagem. Disponível em: http://www.letraefel.com/2009/03/o-estrangeiro-de-albertcamus-filosofia.html

4 A tradução livre para os versos acima é: Estou numa praia/ com uma arma na minha mão/ olhando fixamente para o céu/ Olhando fixamente para a areia. Disponível em: < https://www.letras.mus.br/the-cure/9310/traducao.html>. 
Segunda Guerra Mundial e pelos desafios complexos que ela simultaneamente manifestava e impunha às sociedades ocidentais. Como não poderia deixar de ser, as produções culturais da época foram profundamente marcadas por esse conflito e por seus desdobramentos. Albert Camus participou ativamente desse momento, com uma produção não apenas literária, mas também filosófica cuja relevância representa objeto de estudo até os dias atuais:

Camus participou diretamente dos acontecimentos de seu tempo e, por meio da escrita, teceu uma ácida crítica social ao século XX. Filosofia e linguagem se interpenetram e complementam em $O$ estrangeiro, cunhando uma visão de mundo fundada no absurdo e no sentimento trágico da vida, visão geradora de desconfiança intensa para com aqueles que constroem e lutam para perpetuar os sistemas de valores ${ }^{5}$.

De certa forma, é possível sugerir que Camus insere no temperamento de Meursault uma frieza que pode ser reflexo da própria sociedade vigente, uma sociedade que se constitui através da fuga daquilo que é racional e moralmente aceito:

O personagem Meursault surge como representante do absurdo camusiano que, para Sartre (1968, p. 90), "nascerá da impotência que temos de pensar com os nossos conceitos e com as nossas palavras os acontecimentos do mundo". O homem absurdo camusiano não vive sob os paradigmas da razão e nem da moral estabelecidas, o que pode ser percebido na abertura do livro, quando nos deparamos com o episódio da morte da mãe de Meursault ${ }^{6}$.

Vale ressaltar também que a Argélia, país africano em que o enredo do romance se desenvolve, e também palco de boa parte da produção de Camus, era ainda território francês na época em que foi escrito o romance. Os argelinos passaram a reivindicar a independência do território em 1954, doze anos após a publicação de L'étranger.

Em $1^{\circ}$ de novembro de 1954, foi fundado a Frente de Libertação Nacional (FLN) pelo Comitê Revolucionário de Unidade e Ação (CRUA) 20, que desempenhou o papel de organização político e militar para a obtenção da independência frente à França. A maioria dos partidos nacionalistas se dissolveu e integrou a FLN (SAMPAIO, 2013, p. 32).

\footnotetext{
5 O Estrangeiro de Albert Camus: Filosofia e Linguagem. Disponível em: http://www.letraefel.com/2009/03/o-estrangeirode-albert-camus-filosofia.html. Acesso em: 31/10/2016.

${ }^{6}$ Id. Ibid
}

Killing an Arab, por sua vez, foi lançada em um contexto histórico de crescente xenofobia contra os grupos árabes. A consciência social estava começando a se desenvolver acerca da problemática da imigração e das tensões que elas faziam surgir nas sociedades europeias.

Além disso, com o acirramento da competição comercial, as gravadoras vigentes tinham uma preocupação muito maior em relação ao tipo de música que poderia ser gravada, exigindo cada vez mais qualidade do material produzido pelos artistas. Nesse período, houve uma mudança do método utilizado anteriormente, que consistia em selecionar dez artistas aleatórios, esperar que pelo menos um desses fornecesse lucros e fizesse sucesso, cobrindo o prejuízo causado pelos outros nove artistas, como afirma Friedlander (2002):

No final dos anos 70, importantes tendências econômicas e artísticas estavam afetando 0 modo como a música era criada e vendida. $A$ consolidação da indústria fonográfica continuava a passos firmes; poucos selos, propriedades de grandes corporações, vendiam uma grande percentagem do produto. [...] As listas de músicas executadas nas estações de rádio eram cada vez mais curtas e firmemente controladas, uma vez que a programação das rádios de rock estava sempre concentrada nas mãos de poucos consultores e porque os pequenos mercados tiveram suas indicações dos maiores. Estes fatos conspiravam para dificultar a tarefa dos músicos, aqueles que não eram contratados das grandes gravadoras, se tornarem conhecidos nacionalmente (FRIEDLANDER, 2002, p. 346).

Robert Smith, vocalista da banda The Cure e também compositor de Killing an Arab, indica em uma entrevista de 1987 que compôs a música aos dezesseis anos. Por uma falta de compreensão de DJ's da época, a composição foi chamada de racista:

[...] an antiviolence vignette based on a scene from Albert Camus' book The Stranger - was misinterpreted and adopted as a racist anthem by certain American djs ${ }^{7}$.

As gravadoras da época sugeriram que a faixa fosse retirada da lista de músicas que compunham o

\footnotetext{
7 Em tradução livre para o Português, a citação diz: Uma vinheta ultraviolenta baseada em uma cena do livro $O$ Estrangeiro de Albert Camus foi mal interpretada e adotada como um hino racista por alguns dj's americanos (An Interview With Robert Smith of The Cure. Disponível em: http://www.musicfanclubs.org/cure/press/l94.html).
} 
primeiro disco da banda. Smith, para esclarecer o impasse, fez uma declaração explicando que a letra da canção tratava da retomada de um trecho da obra de Camus. Por questão de princípios, o compositor se recusava a ter um álbum lançado sem que essa faixa estivesse presente no disco:

There were other ways out of it, but they all would have been more painful for us. We could have insisted that everything stay as it was, but I had to make a gesture that people would understand. I just despaired, really, that I had to step in and explain, and I got very annoyed at Elektra's initial suggestion that they delete the song but keep selling the album, which we refused to do. I said that they could delete the album if they wanted to, but they couldn't take the song off (Id Ibid) ${ }^{8}$.

\section{Traços de Intertextualidade em Killing an} Arab

Segundo Koch (2012), o contexto é essencial na criação de sentido por parte do leitor, pois é somente através dessa interação que se torna possível a interpretação. A construção do texto se inicia a partir do momento em que o leitor entra em contato com seu conteúdo e produz sentido para a narrativa através de suas experiências e vivências pessoais.

Considerando a afirmação de Koch no contexto da transposição midiática do romance para a música, é possível dizer que a interpretação de Killing an Arab por parte de um ouvinte (ou leitor da letra da música) será diferente caso ele tenha lido, ou ao menos ouvido falar de L'étranger previamente. Neste caso, além de haver a interação texto-leitor, haverá também a possibilidade de uma referenciação entre obras, o que o capacitará para criar interpretações diferentes de alguém que desconhecesse a obra de Camus:

Defende-se, hoje em dia, a posição de que a referenciação, bem como a posição referencial, consiste da construção e reconstrução de objetos de discurso. Ou seja,

\footnotetext{
${ }^{8}$ Em tradução livre, Robert Smith diz: "Havia outros meios para sair disso, mas todos teriam sido mais dolorosos para nós. Nós teríamos insistido que tudo ficasse como era, mas eu tive que fazer um gesto que as pessoas entendessem. Eu me desesperei, muito, porque tinha que me envolver na situação e explicar, e fiquei muito irritado com a sugestão inicial do Elektra, de excluir a música mas manter a venda do álbum, o que nós nos recusamos a fazer. Eu disse que eles podiam excluir o álbum, se quisessem, mas que não poderiam tirar a música.
}

os referentes de que falamos não espelham diretamente o mundo real, não são simples rótulos para designar as coisas do mundo. Eles são construídos e reconstruídos no interior do próprio discurso, de acordo com a nossa percepção do mundo, nossos "óculos sociais" (BLIKSTEIN, 1986, apud KOCH, 2012, p. 123).

Quando há análise de dois textos que estão relacionados entre si por exibirem semelhanças importantes, ou pelo fato do texto produzido depois apresentar referências (evidentes ou não), é possível dizer que existe entre eles uma relação de intertextualidade ${ }^{9}$.

Para Marcuschi (2008), a intertextualidade é: "a propriedade constitutiva de qualquer texto e o conjunto das relações explícitas ou implícitas que um texto ou um grupo de textos determinado mantém com os outros textos" (MARCUSCHI, 2008, p. 30). O autor ainda afirma haver um consenso de que todos os textos existentes estão associados de alguma maneira com outros textos, tornando-os assim, todos envolvidos de aspectos intertextuais (MARCUSCHI, 2008, p. 30).

Com base nesse conceito, pode-se afirmar que o romance de Camus e a letra da música da banda The Cure estão associadas por meio da intertextualidade, principalmente pelo fato de apresentarem uma temática semelhante em trechos específicos.

$\mathrm{KOCH}$ (2012), afirma que há dois tipos de intertextualidade, uma explícita, em que há referências à obra original de forma evidente e outra implícita:

A intertextualidade implícita ocorre sem citação expressa da fonte, cabendo ao interlocutor recuperá-la na memória para construir o sentido do texto, como nas alusões, na paródia, em certos tipos de paráfrases e ironias (cf. KOCH, 1991, 1997 a e b, 2004, p. 92).

É possível então considerar que o tipo de intertextualidade contida em Killing an Arab é implícita, uma vez que não há nenhuma referência direta à L'étranger na letra da música, o que, como já foi dito anteriormente, trouxe alguns problemas aos

\footnotetext{
9 Vale ressaltar que, primeiro texto aqui é praticamente metafórico, pois não há como considerar um texto sendo o "embrionário". Um texto sempre recupera outro texto, como afirma Marcuschi (2008).
} 
integrantes da banda por terem sido considerados xenofóbicos, antes que pudessem explicar a origem da letra musical.

\section{Intermidialidade: L'étranger (mídia fonte),} Killing an Arab (mídia alvo)

Gaudreault e Marion (2008, p. 107), iniciam seu artigo sobre questões ligadas à intermidialidade com a seguinte indagação: "é possível uma história em espécie de estado virgem, original, anterior a qualquer encarnação midiática?" Essa questão possibilita uma discussão a respeito da ideia de haver ou não a existência de uma primeira obra criada, que dá margem para criações posteriores que a tomem por base.

Segundo Clüver (2007), como conceito, "intermidialidade" implica todos os tipos de interrelação e interação entre mídias; uma metáfora frequentemente aplicada a esses processos fala de "cruzar as fronteiras" que separam as mídias.

Tem-se aqui já uma pequena consideração sobre como as duas obras analisadas podem estar enquadradas no conceito de intermidialidade. Há dois trabalhos artísticos produzidos em diferentes contextos sócio-históricos e culturais e que também diferem no que tange ao gênero que pertencem. Não obstante, há entre ambos um evidente "cruzamento de fronteiras", uma vez que abordam temas semelhantes, o assassinato de um árabe em uma praia, num dia quente.

Para uma melhor contextualização do termo intermidialidade, Rajewsky (2012, p. 15), afirma que o termo já era utilizado com frequência na Alemanha, e que na década de 1990, foi transferido para a língua inglesa, de modo a ser muito mais disseminado no mundo todo a partir desse momento. Seu artigo aborda de forma muito abrangente três subcategorias possíveis de intermidialidade.

A primeira subcategoria definida por Rajewsky, refere-se à intermidialidade como transposição midiática. Ela se apresenta nas adaptações literárias, por exemplo de um texto para um filme. "Essa categoria é uma concepção de intermidialidade "genética", voltada para a produção (Id. Ibid., p. 24) ${ }^{10}$.

A partir dessa definição, é possível enquadrar as duas obras em análise nessa primeira subcategoria, se forem consideradas questões como a existência de uma mídia fonte (L'étranger) e uma mídia alvo (a música Killing an Arab) ${ }^{11}$.

O conceito de transmodalização, conforme proposto por Genette (2006), ajuda a melhor entender esse processo:

Por transmodalização, entendo, portanto, mais modestamente, uma transformação no que tem sido designado, desde Platão e Aristóteles, modo de representação de uma obra de ficção: narrativo ou dramático (GENETTE, 2006, p. 119).

$\mathrm{O}$ autor define que as transformações modais podem acontecer de duas maneiras: intermodais (passagem de um modo a outro) ou intramodais (mudança interna no funcionamento de um modo). Pode-se considerar então a análise presente como sendo de natureza intermodal, uma vez que há primeiramente 0 modo textual romance, que posteriormente é transformado em canção.

\section{Análise comparativa de trechos selecionados: contextualização das cenas}

Os trechos que dialogam entre as duas obras se relacionam através da narração de uma situação vivida pelo protagonista, em uma praia. Em L'étranger, a cena ocorre no capítulo VI da primeira parte do romance, enquanto que em Killing an Arab, o desdobramento da cena se dá ao longo de todas as estrofes da canção.

No romance, a situação se inicia quando Meursault, com sua namorada Marie, decide ir à praia em um domingo de calor. Ao encontrarem um amigo

\footnotetext{
10 A segunda subcategoria tem a ver com a combinação de mídias. Para a autora, essa definição está relacionada com a possibilidade de combinar ao menos duas mídias distintas com o intuito de criar um produto. A terceira subcategoria é denominada referências intermidiáticas. Tem a ver com a "evocação ou imitação de certas técnicas cinematográficas como tomadas de zoom, dissolvências, fades e edição de montagem (Id. Ibid.). Essas duas subcategorias não se aplicam a essa pesquisa e portanto não serão consideradas nesse trabalho.

11 Além de ser uma composição textual musicada, também possui videoclipe. $\mathrm{O}$ foco deste artigo será voltado à música.
} 
do protagonista, chamado Raymond, inicia-se o conflito que se desenvolve nas cenas posteriores: ao caminharem na rua, as personagens se deparam com um grupo de árabes com quem Raymond havia tido um desentendimento:

J'ai vu un groupe d'Arabes adossés à la devanture du bureau de tabac. Ils nous regardaient en silence, mais à leur manière, ni plus ni moins que si nous étions des pierres ou des arbres morts. Raymond m'a dit que le deuxième à partir de la gauche était son type, et il a eu l'air préoccupé (CAMUS, 2015, p. $77)^{12}$.

$\mathrm{Na}$ continuação da cena, o trio se encaminha de ônibus à casa de praia de Masson, um amigo de Raymond. Meursault, Marie, Raymond, Masson e sua esposa estão juntos e se dirigem à praia. Após o passeio, retornam à casa para almoçar e, em um segundo momento, somente os homens voltam à praia:

Marie a déclaré qu'elle resterait pour aider Mme Masson à faire la vaisselle. La petite Parisienne a dit que pour cela, il fallait mettre les hommes dehors. Nous sommes descendus tous les trois (CAMUS, 2015, p.83) $)^{13}$.

Nota-se, a partir desse trecho que, gradativamente, o número de pessoas que se dirigem à praia diminui a cada vez que essa ação é retomada. É também a partir desse momento que uma tensão maior vai se instalando com uma aceleração da sequência de eventos: as conversas entre Masson e Raymond (supostamente amigos há muitos anos) incompreensíveis para Meursault, os dois árabes surgem caminhando na areia; a confirmação por parte de Raymond de que um deles é o mesmo visto no início do capítulo, com quem o personagem possui um conflito:

À ce moment, Raymond a dit à Masson quelque chose que j'ai mal entendu. Mais j'ai aperçu en même temps, tout au bout de la plage et très loin de nous, deux Arabes en bleu de chauffe qui venaient dans notre

\footnotetext{
12 Vi um grupo de árabes encostado na vitrina de uma tabacaria. Olhavam-nos em silêncio, mas à maneira deles, como se fossêmos pedras ou árvores mortas. Raymond disseme que o sujeito era o segundo a contar da esquerda, e ficou com uma expressão preocupada (CAMUS, 2013, p. 52).

${ }^{13}$ Marie declarou que ficaria para ajudar a Sra. Masson a lavar a louça. A pequena parisiense disse que para isso era preciso pôr os homens para fora. Descemos os três (CAMUS, 2013, p. 55).
}

direction. J'ai regardé Raymond et il m'a dit "C'est lui» (CAMUS, 2015, p. 84) ${ }^{14}$.

Os dois grupos caminham um em direção ao outro e como se já anunciada, uma briga se inicia. Um dos árabes possui uma faca e Raymond é ferido, obrigando o grupo a retornar à casa. A cena tem sequência com a volta de Raymond e Meursault do hospital que decidem ir à praia uma terceira vez, onde acabam encontrando os dois árabes novamente:

Nous avons marché longtemps sur la plage. Le soleil était maintenant écrasant. II se brisait en morceaux sur le sable et sur la mer. J'ai eu l'impression que Raymond savait où il allait, mais c'était sans doute faux. Tout au bout de la plage, nous sommes arrivés enfin à une petite source qui coulait dans le sable, derrière un gros rocher. Là, nous avons trouvé nos deux Arabes (CAMUS, 2015, p. 87) ${ }^{15}$.

Nota-se nesse trecho que o narrador se refere aos dois árabes pelo pronome possessivo "nossos", como se os homens fossem propriedade de Meursault e Raymond. Em relação aos possessivos, Charaudeau indica que:

Les possessifs s'inscrivent dans une opération sémantique qui consiste à établir une relation d'interdépendance entre, au moins, deux éléments qui peuvent se trouver dans une combinaison d'appartenance (avoir) ou d'actante (faire). Dans cette mise en interdépendance, les possessifs permettent de préciser qu'il existe un lien étroit entre l'un des éléments, dépendant, et l'autre qui joue le rôle de pôle de référence. En outre, ils signalent que la relation d'interdépendance est présupposée et que le pôle de référence est supposé connu. (CHARAUDEAU, 1992, p. $195)^{16}$

No texto de Camus, cria-se uma relação de interdependência entre o narrador, Raymond (polos

\footnotetext{
${ }^{14}$ Nesse momento, Raymond disse a Masson alguma coisa que não consegui ouvir muito bem. Mas percebi, ao mesmo tempo, no fim da praia e muito longe de nós, dois árabes de macacões azuis, que vinham na nossa direção. Olhei para Raymond e ele me disse:

- É ele (CAMUS, 2013, p. 55).

15 Tive a impressão de que Raymond sabia aonde ia, mas talvez estivesse enganado. Lá no fim da praia chegamos finalmente a uma pequena fonte que brotava na areia, por trás de um grande rochedo. Aí, encontramos nossos dois árabes (CAMUS, 2013, p. 57)

${ }^{16}$ Os possessivos se inscrevem em uma operação semântica que consiste em estabelecer uma relação de interdependência entre, ao menos, dois elementos que podem se encontrar em uma combinação de pertencimento (ter) ou de actante (fazer). Nessa relação de interdependência, os possessivos permitem precisar que existe um laço estreito entre um dos elementos, dependente, e o outro que tem o papel de polo de referência. Além disso, eles assinalam que a relação de interdependência é pressuposta e que o polo de referência é suposto conhecido (CHARAUDEAU, 1992, p. 195, tradução nossa).
} 
de referência) e os árabes (dependentes). Essa relação se mostra pressuposta, pois o leitor já conhece 0 episódio anterior da disputa entre Raymond e o árabe.

Em seguida, os personagens cogitam a ideia de utilizar um revólver contra os dois árabes, porém somente em caso de uma briga com faca ser iniciada novamente. Como essa situação não chega a ser consumada, Raymond e Meursault retornam mais uma vez à casa de Masson. É importante notar o vai e vem dos personagens entre a praia e a casa. Esse deslocamento confere ritmo à narrativa e representa peça fundamental para a construção do clímax final.

Nesse momento, ocorre um último retorno à praia, culminando assim a gradativa redução de personagens, deixando somente Meursault na ação. Ao caminhar pela praia, o narrador e protagonista avista novamente um árabe, e mesmo alegando que acreditava ser a situação um "caso encerrado", carregava consigo o mesmo revólver da cena anterior:

II était seul. II reposait sur les dos, les mains sous la nuque, le front dans les ombres du rocher, tout le corps au soleil. Son bleu de chauffe au fumait dans la chaleur. J'ai été un peu surpris. Pour moi, c'était une histoire finie et j'étais venu là sans y penser. Dès qu'il m'a vu, il s'est soulevé un peu et a mis la main dans sa poche. Moi, naturellement, j'ai serré le revolver de Raymond dans mon veston (CAMUS, 2015, p. 91) ${ }^{17}$.

Como habitual em narrativas construídas a partir do ponto de vista subjetivo, é o próprio narrador quem anuncia que, impelido pelo calor excessivo na praia, assassina o árabe com o revólver de Raymond:

Tout mon être s'est tendu et j'ai crispé ma main sur le revolver. La gâchette a cédé, j'ai touché le ventre poli de la crosse et c'est là, dans le bruit à la fois sec et assourdissant, que tout a commencé. J'ai secoué la sueur et le soleil. J'ai compris que j'avais détruit l'équilibre du jour, le silence exceptionnel d'une plage où j'avais été heureux. Alors, j'ai tiré encore quatre fois sur un corps inerte où les balles s'enfonçaient sans qu'il y parût. Et c'était comme quatre coups brefs que je

\footnotetext{
${ }^{17}$ Estava só, descansava de costas as mãos debaixo da nuca, a cabeca nas sombras do rochedo, todo o corpo ao sol. Seu macacão azul fumegava ao calor. Fiquei muito surpreso. Para mim, era um caso encerrado, e viera para cá sem pensar nisso. Logo que me viu, ergueu-se um pouco e meteu a mão no bolso. Eu, naturalmente, agarrei o revólver de Raymond dentro do paletó (CAMUS, 2013, p. 59).
}

frappais sur la porte du malheur. (CAMUS, 2015 , p. 93$)^{18}$

Com o trecho acima, encerra-se a primeira parte do romance, Meursault atira quatro vezes sobre o corpo já inerte do árabe e reage de forma "estranha, estrangeira" ao assassinato. A sequência, na segunda parte do romance, narra sua prisão e julgamento.

Na música, a construção do cenário da praia se dá de forma mais simples. Não há uma diminuição gradativa de personagens na cena, como em L'étranger. Nessa obra, há somente o personagem principal, que é também o narrador. Como dito anteriormente, não é possível afirmar que seu nome seja Meursault, pois isso não é dito em nenhum dos versos da canção.

A primeira estrofe da música já explicita o cenário: as ações do narrador, a presença de uma arma em sua mão, a observação do local e também a presença de um árabe:

I'm standing on a beach

With a gun in my hand

Staring at the sky

Staring at the sand

Staring down the barrel

At the arab on the ground

See his open mouth

But I hear no sound ${ }^{19}$,

É possível supor o anúncio do assassinato já na primeira estrofe da música, se forem comparados os três últimos versos (em que o árabe está no chão, com a boca aberta, mas não há nenhum som) com o trecho do romance em que Meursault atira quatro vezes, em um corpo já inerte no chão.

Esse anúncio precoce quebra o suspense que é criado no romance, em que até o último momento do capítulo, há incertezas sobre o ato de assassinato por parte do protagonista da história.

\footnotetext{
18 Todo o meu ser se retesou e crispei a mão sobre o revólver. O gatilho cedeu, toquei o ventre polido da coronha e foi aí, no barulho ao mesmo tempo seco e ensurdecedor, que tudo começou. Sacudi o suor e o sol. Compreendi que destruíra o equilíbrio do dia, o silêncio excepcional de uma praia onde havia sido feliz. Então atirei quatro vezes ainda num corpo inerte em que as balas se enterravam sem que se desse por isso. $\mathrm{E}$ era como se desse quatro batidas secas na porta da desgraça (CAMUS, 2013, p 60).

19 Parado na praia / Com uma arma em minha mão/ Olhando fixamente para o mar/ Olhando fixamente para a areia/ Olhando fixamente para o cano/ Do árabe no chão/ Vejo sua boca aberta/ Mas não escuto nenhum som (tradução da autora).
} 


\section{A influência do cenário no assassinato do personagem árabe}

A partir da análise de L'étranger, é possível estabelecer que o crime cometido por Meursault é afetado, ao longo de todo o capítulo VI, majoritariamente por questões ambientais e climáticas.

Observa-se, desde o primeiro capítulo, que as altas temperaturas estão sempre influenciando as reações do protagonista: o personagem retoma repetidamente esse tema: "J'ai pris l'autobus, il faisait très chaud” (CAMUS, 2015, p. 10) 20.

As altas temperaturas aparecem constantemente no sexto capítulo, estando muitas vezes representadas por figuras de linguagem, como nesse trecho: "Nous avons marché longtemps sur la plage. Le soleil était maintenant écrasant” (Id. Ibid, p. $87)^{21}$.

Silva (2013), afirma:

Influenciado pelo forte sol que claramente o perturbava no momento em que chegou à fonte, Meursault faz uma análise das coisas que estão à sua volta enquanto repara nos movimentos do árabe que será morto por ele. O personagem está muito sensível ao sol, ao calor e às menores sensações dos elementos naturais que o rodeiam. Camus transmite ao leitor a importância que a cena do crime ocupa no romance por meio do vocabulário e expressões usadas pelo narrador e ainda mediante a ligação direta do sol, do calor e do mar com as atitudes e movimentos de Meursault (SILVA, 2013, p. 89).

O próprio Meursault acaba por confirmar, depois do assassinato, que o calor o impeliu a cometer o crime. Em uma cena em que está sendo interrogado, na segunda parte do livro, o juiz pergunta «Pourquoi avez-vous attendu entre le premier et le second coup?»(CAMUS, 2015, p. 104) 22 o que leva à reflexão de Meursault: "Une fois de plus, j'ai revu la plage rouge et j'ai senti sur mon front la brûlure du soleil. Mais cette fois, je n'ai rien répondu" (Id. Ibid) ${ }^{23}$.

\footnotetext{
20 Peguei o ônibus às duas horas. Fazia muito calor (CAMUS, 2013, p. 13).

21 Andamos muito tempo pela praia. O sol estava agora esmagador (Id. Ibid., p. 57).

22 - Por que esperou entre o primeiro e o segundo tiro? (Id. Ibid., p. 67).

${ }^{23}$ Mais uma vez, revi a praia vermelha e senti o sol queimar-me a testa. Mas desta vez, nada respondi (Id. Ibid)
}

Mesmo que a narrativa leve o leitor a acreditar que Meursault simplesmente não se importa com nada ao longo de todo o romance, é importante destacar que a narrativa de Camus vai muito além desse estado psicológico da personagem. $\mathrm{O}$ absurdo camusiano tem muito mais a ver com o enaltecimento da natureza do que com um foco no ser humano propriamente dito. Nesse momento, o sol, o calor e a areia ganham proporções gigantescas na perspectiva do narrador, aparecendo constantemente em suas descrições e sendo esses os elementos contribuintes para que de fato ocorra um assassinato na praia.

Em Killing an Arab, o cenário e a observação do protagonista são recorrentes em várias estrofes e para isso o autor usa como artifício a repetição das descrições da paisagem. Pode-se sugerir que essa estratégia narrativa visa retomar a insistência indicada por Camus e reforçar o quanto o local e suas características são importantes na consumação do assassinato:
Feel the steel butt jump
Smooth in my hand
Staring at the sea
Staring at the sand
Staring at myself
Reflected in the eyes of
The dead man on the beach $^{24}$

Na canção, o personagem olha para a areia, para o mar e para o sol, assim como o faz Meursault, mas também olha para si mesmo, através dos olhos do cadáver na praia. Vale lembrar que essa ação dialoga com a frase final da cena do assassinato do árabe por Meursault "Et c'était comme quatre coups brefs que je frappais sur la porte du malheur' (CAMUS, 2015, p. 91). Mesmo que a personagem camusiana não explicite um olhar para si mesma, ela tem consciência de que este ato inicia uma nova fase em sua vida, a da desgraça.

Voltando à letra de Smith, o paralelismo presente nos versos provoca a sensação de repetição e reforço das ações realizadas pelo eu-lírico da canção. Essas repetições podem ser comparadas à forma de Meursault sempre retomar e enfatizar a

\footnotetext{
24 Senti a arma disparar /Acalmando minha mão/ Olhando fixamente para o mar/ Olhando fixamente para a areia/ Olhando fixamente para eu mesmo/ Refletido nos olhos/ O homem morto na praia
} 
ideia de calor que o exaspera ao longo de todas as suas idas à praia, até consumar o assassinato.

Além disso, o homem morto na praia, apesar de ter na canção a função de refletir a imagem do próprio eu-lírico, apresenta semelhanças com o corpo inerte do árabe em L'étranger: um corpo que, mesmo já sem vida, é capaz de produzir sons quando é atingido pelas balas, o que para Meursault também tem um efeito, não de reflexo, mas do destino da própria desgraça.

\section{Quem é o verdadeiro Estrangeiro?}

Em um primeiro momento, ao ler L'étranger, é possível afirmar que o estrangeiro da obra é o árabe assassinado por Meursault, pelas próprias definições da palavra. Contudo, em uma leitura mais cuidadosa do romance, o árabe apresenta pouquíssimas características que possibilitam caracterizá-lo até mesmo como o melhor candidato para esse lugar narrativo.

Para Silva (2013), a sociedade em que Meursault vive, faz dele o próprio estrangeiro. Suas principais características fazem parte da composição do que é chamado de "absurdo camusiano":

Utilizando os atos do personagem Meursault como base para nosso trabalho de pesquisa, analisamos valores como a honestidade, as aspirações materiais e seu modo de agir descontextualizado da sociedade, que o vê como um estrangeiro. Analisamos ainda 0 modo de vida simples que o personagem leva, composto apenas de algumas necessidades como comer, fumar e dormir. Ressaltamos também suas respostas indiferentes, a ausência de emoções aparentes e o tédio que são elementos do cotidiano absurdo (Silva, 2013, 20).

O personagem parece estar sempre alheio às situações ao seu redor, desde o velório e enterro de sua mãe, até sua prisão por assassinato, o que lhe confere a caracterização de estrangeiro à sociedade em que vive.

Essas características têm forte relação com 0 estilo de escrita de Albert Camus. A estranheza que as personagens causam ao leitor, não somente em L'étranger, compõe os principais elementos desse estilo. Toda a sensação de que os personagens que compõem a narrativa não se incomodam com a apatia uns dos outros, ou que vivem em razão de elementos naturais muito mais do que de elementos sociais, como uma promoção no emprego ou o aceite a um pedido de casamento, são na realidade uma crítica à sociedade em que Camus estava introduzido, uma sociedade repleta de códigos e leis, como aponta Olivo (2007):

A maneira de assim situar sua personagem principal denuncia a crítica aguda que Camus faz da sociedade e dos pactos que o homem estabelece - ou nega - para nela sobreviver. A vida nesta sociedade é considerada absurda, pois somos todos obrigados a nos submeter a regras, a uma moral, a um código, que nem sempre estão de acordo com nossa condição humana. O conjunto das leis é a maior obra de ficção que o homem criou. Claro que do outro lado o que existe é o caos, mas Camus tenta mostrar o que há entre o caos suposto e a ordem estabelecida (OLIVO, 2007, p. 149).

Meursault é, sem dúvidas, um personagem absurdo e que vive sem pensar em regras, conduzido pela vida, sem um objetivo claro. Isso pode ser verificado em um dos trechos do capítulo $\mathrm{V}$ da obra: Marie, namorada de Meursault, o questiona sobre um possível casamento dos dois. Ela recebe uma resposta de tom indiferente, sem expressões sentimentais marcantes:

Le soir, Marie est venue me chercher et m'a demandé si je voulais me marier avec elle. J'ai dit que cela m'était égal et que nous pourrions le faire si elle le voulait. Elle a voulu savoir alors si je l'aimais. J'ai répondu comme je l'avais déjà fait une fois, que cela ne signifiait rien mais que sans doute je ne l'aimais pas $^{25}$ (CAMUS,2015, p. 67).

São esses elementos que também fazem o personagem principal estar na condição de estrangeiro dentro de seu próprio país e entre as pessoas que o conheceram ao longo de sua vida, desde o velório da sua mãe até a sua condenação.

Em se tratando de Killing an Arab, existe um eu-lírico que se auto-identifica como estrangeiro (ou estranho, pois a palavra stranger na língua inglesa pode ser traduzida das duas maneiras como em francês):

25 À noite, Marie veio buscar-me e perguntou se eu queria casar-me com ela. Disse que tanto fazia, mas que se ela queria poderíamos nos casar. Quis, então, saber se eu a amava. Respondi, como aliás já respondera uma vez, que isso nada queria dizer, mas que não a amava (CAMUS, 2013, p. 46). 
I'm alive

I'm dead

I'm the stranger

Killing an $\mathrm{Arab}^{26}$

Além de confessar ser o próprio estrangeiro, o eu-lírico da canção o faz colocando-se em paralelo à ação de matar o árabe. Há a confusão entre estar vivo ou estar morto, que em relação ao árabe assassinado, acaba por causar uma situação de paralelismo.

\section{Considerações finais}

Este artigo foi realizado com o objetivo de aprofundar questões teóricas que identifiquem como duas mídias distintas cruzam fronteiras e dialogam. 0 objetivo foi o de buscar por evidências concretas como a música da banda The Cure foi construída como uma nova mídia, baseada na obra de Camus, enquanto mídia fonte.

O estudo realizado oferece algumas respostas em relação ao diálogo entre as duas obras, sendo a maioria delas relacionadas ao conceito de intermidialidade. Pode-se afirmar que Robert Smith, leitor de Camus, em especial de L'étranger, se apropriou de elementos estéticos do absurdo literário para compor Killing an Arab. A partir dessa expectativa, Smith propôs uma releitura de L'étranger de forma concisa, o que, a princípio, induziu a erro diversas pessoas desinformadas sobre a obra de Camus, que classificaram a música como xenofóbica, até que houvesse um esclarecimento por parte do compositor.

Apesar dos modos de escrita dos dois autores diferirem em diversos aspectos, é preciso observar que muitos elementos aproximam as duas obras. Entre eles, os principais são: a manutenção de uma narrativa partindo de um personagem principal que, em dado momento vai a uma praia e ali mata um árabe. Também são preservadas questões de ordem cenográficas, um local semelhante nos trechos analisados das duas obras, assim como questões de ordem psicológica, já que ambos os personagens

\footnotetext{
${ }^{26}$ Estou vivo/ Estou morto/ Eu sou o estrangeiro/ Matando um árabe
}

cometem o assassinato de forma quase natural, a despeito de, no momento mesmo do homicídio, já terem uma visão do futuro: a ruína.

\section{Referências}

An Interview With Robert Smith of The Cure. Disponivel em: $<$ http://www.musicfanclubs.org/cure/press/l94.html >. Acesso em 31/10/2016.

BAKHTIN, M. Os Gêneros do discurso. In: Estética da criação verbal. São Paulo, Martins Fontes: 1997.

Biografia. O Estrangeiro: site brasileiro sobre Albert Camus. Disponível em: <http://www.albertcamus.com.br/2010/07/biografia. html >. Acesso em: 15/12/2016.

CAMUS, Albert. L'étranger. Barcelona, Folio: 2015.

CAMUS, A. O Estrangeiro. Tradução de Valerie Rumjanek. Rio de Janeiro, BestBolso: 2013.

CARDOSO, L.M. A Problemática do Narrador: da literatura ao cinema. Minas Gerais, UFJF: 2003.

CHARAUDEAU, P. Grammaire $d u$ sens et de l'expression. Paris, Hachette Livres, 1992.

CLÜVER, C. Inter textus/ Inter artes/ Inter media. Disponível em: <http://www.letras.ufmg.br/poslit. Acesso em: 18/05/2017.

FRIEDLANDER, P. Os anos 70: diluição e transformação. In: Rock and Roll: uma história social. Rio de Janeiro, Record: 2002.

GAUDREAULT, A. \& MARION P. Transescritura e Midiática Narrativa: questões de intermedialidade. In: Diniz, T. Intermidialidade e Estudos Interartes: desafios da arte contemporânea. Belo Horizonte, UFMG: 2008. p. 107-126.

GENETTE, G. Figures III. Paris, Seuil: 1972.

GENETTE, G. Palimpsestos: a literatura de segunda mão. 2ed. Belo Horizonte, UFMG: 2006.

$\mathrm{KOCH}$, I.V.; Elias, V.M. Ler e compreender os sentidos do texto. 3ed. 7 reimpr. São Paulo, Contexto: 2012.

MARCUSCHI, L.A. Gêneros textuais no ensino da língua. In: Produção textual, análise de gêneros e compreensão. 1 ed. 7 reimpr. São Paulo, Parábola: 2008.

MENEGHELLO, H.C. A transposição intersemiótica. UFSC, 2014. ISSN 2176-7904. 
O Estrangeiro de Albert Camus: Filosofia e Linguagem. Disponível em: < http://www.letraefel.com/2009/03/o-estrangeiro-dealbert-camus-filosofia.html>. Acesso em: $31 / 10 / 2016$.

OLIVO, C.V.C. O princípio do prazer de Meursault em O Estrangeiro de Albert Camus. Fragmentos, n.33, Florianópolis: 2007.

RAJEWSKY, Irina O. Intermidialidade, Intertextualidade e "Remediação": uma perspectiva literária sobre a intermidialidade. In: Diniz, T.F.N. Intermidialidade e Estudos Interartes: desafios da arte contemporânea. Belo Horizonte, UFMG: 2012.
ROSENFELD, Anatol. Texto/Contexto. 3 ed. São Paulo: Perspectiva, 1976.

SAMPAIO, H. S. O discurso de Jean-Paul Sartre sobre o colonialismo francês e a Guerra de Independência da Argélia (1954 - 1962). Vol. 6 nำ1, UNESP Marília: 2013.

SILVA, A.R.B. A indiferença e o sol: Meursault, o herói absurdo em $\mathrm{O}$ Estrangeiro de Albert Camus. Vitória, EDUFES: 2013.

The Cure. Killing an Arab. Disponível em: $<$ https://www.letras.mus.br/thecure/9310/traducao.html>. Acesso em 30/10/2016.

\section{COMO CITAR ESSE ARTIGO}

DOS SANTOS, Victória Elizabeth; GHIRARDI, Ana Luiza Ramazzina. L'étranger e a transposição midiática Killing an Arab. Signo, Santa Cruz do Sul, v. 43, n. 76, mar. 2018. ISSN 1982-2014. Disponível em: <https://online.unisc.br/seer/index.php/signo/article/view/10676>. Acesso em: doi: http://dx.doi.org/10.17058/signo.v43i76.10676. 


\section{ANEXO}

\section{Killing An Arab}

I'm standing on a beach

With a gun in my hand

Staring at the sky

Staring at the sand

Staring down the barrel

At the arab on the ground

See his open mouth

But I hear no sound

I'm alive

I'm dead

I'm the stranger

Killing an arab

I can turn and walk away

Or I can fire the gun

Staring at the sky

Staring at the sun

Whichever I choose

It amounts to the same

Absolutely nothing

I'm alive

I'm dead

I'm the stranger

Killing an arab

Feel the steel butt jump

Smooth in my hand

Staring at the sea

Staring at the sand

Staring at myself

Reflected in the eyes of

The dead man on the beach

The dead man on the beach

I'm alive

I'm dead

I'm the stranger

Killing an arab 